\title{
PALAVRA ABERTA - BNCC E A ALFABETIZACÃO EM DUAS VERSÕES: CONCEPÇÕES E DESAFIOS
}

ISABEL CRISTINA ALVES DA SILVA FRADE'

ORCID: https://orcid.org/0000-0003-0805-7581

I Universidade Federal de Minas Gerais, Programa de Pós-Graduação em Educação, Belo Horizonte, MG, Brasil.

Isabel C. A. da S. Frade - Doutora em Educação pela Universidade Federal de Minas Gerais. Professora titular do Programa de Pós-Graduação em Educação da FAE-UFMG. Pesquisadora do Centro de Alfabetização Leitura e Escrita da FAE-UFMG. Belo Horizonte, Minas Gerais. Brasil.

E-mail:<icrisfrade@gmail.com>.

RESUMO: Fruto de meta estabelecida pelo Plano Nacional de Educação (2014) e de outros antecedentes legais, a Base Nacional Comum Curricular (BNCC) provocou inúmeras disputas, discordâncias e acordos desde seu projeto inicial até a sua formulação final, e esse movimento trouxe consequências específicas para o discurso sobre a alfabetização no Brasil. $\mathrm{O}$ artigo busca problematizar as questões envolvidas na formulação de uma proposta de alfabetização para a BNCC, fazendo uma recuperação das interpretações, concepções, problemas e algumas soluções em jogo na formulação da segunda versão da BNCC e um contraste com a sua versão homologada Serão problematizados a especificidade da alfabetização e o seu diálogo com outras perspectivas postas para o ensino de Língua Portuguesa nos anos iniciais do ensino fundamental. Pretende-se discutir também a natureza do texto homologado e possíveis brechas que os sistemas de ensino e os professores encontrarão para dialogar com o documento normativo e mandatório da BNCC.

Palavras-chave: Alfabetização. Base Nacional Comum Curricular. Língua Portuguesa.

\section{BNCC AND LITERACY IN TWO VERSIONS: CONCEPTIONS AND CHALLENGES}

ABSTRACT: As a result of the National Education Plan (2014) and other legal precedents, the Common National Curricular Basis (BNCC) has provoked numerous disputes, disagreements and agreements from its initial project to its final formulation, and this movement has brought specific consequences for the discourse on literacy in Brazil. The article seeks to problematize the 
issues concerning the formulation of a literacy proposal for the BNCC, making a recovery of the interpretations, conceptions, problems and some solutions at stake in the formulation of the second version of BNCC, and establishing a contrast with the final version. The specificity of literacy and its dialogue with other perspectives put forward for Portuguese language teaching in the initial years of Elementary School will be problematized. It is also intended to discuss the nature of the certified text and possible gaps that the education system and teachers will encounter in order to dialogue with the normative and mandatory document of the BNCC.

Keywords: Literacy. Common National Curricular Basis. Portuguese language.

\section{INTRODUÇ̃̃̃}

O intenso debate nacional sobre a Base Nacional Comum Curricular (BNCC), no decorrer dos anos de 2015 e 2016, já estava previsto na Constituição Federal, na Lei de Diretrizes e Bases (LDB), e depois viria a ser reforçado nas Diretrizes Curriculares Nacionais para a Educação Básica (DCNs). Todas essas legislações ou documentos complementares foram desenvolvidos num momento em que a sociedade brasileira aspirava e praticava a democracia, uma vez que a própria legislação vigente garante a liberdade de ensinar e o respeito às diferenças e indicava os direitos essenciais a serem atingidos pela educação. Quase vinte anos após a promulgação da LDB, como parte do esperado debate, foi produzido o Plano Nacional de Educação 20142024 (PNE), que levou ao estabelecimento de metas relativas à BNCC.

As disputas em torno da BNCC foram de ordem política, conceitual e pedagógica: seria necessário ter ou não ter uma BNCC? Qual seria o seu significado? Sua existência colocaria em risco a autonomia dos sistemas e dos professores? Com ela, seria possível trabalhar a diversidade? Sem um consenso sobre o que seria um currículo e o papel da BNCC nessa construção, muitos consideravam que, existindo os Parâmetros Curriculares Nacionais (PCNs) ou as Diretrizes Curriculares para a Educação Básica, não seria necessário construir um novo documento (BATISTA e RIBEIRO, 2015). De um ponto de vista da leitura e interferências nos rumos dos documentos, houve disputas entre entidades científicas e paradigmas epistemológicos; entre os defensores dos direitos mais amplos e os defensores das especificidades e diversidades; entre esses grupos e o movimento Escola sem Partido; ${ }^{1}$ bem como entre sujeitos da educação pública e setores de iniciativa privada.

Embora houvesse comissões anteriores que tentaram formular alguns documentos no MEC, a partir da meta 7.1 do Plano Nacional 
de Educação a equipe que foi chamada a contribuir com a versão que foi à consulta pública, teve início em junho de $2015 .^{2}$ Entre a primeira e a segunda versões da BNCC, o clima político no Brasil, às vésperas do impeachment de Dilma Rousseff, demandou um grande esforço e urgência em entregar a segunda versão no dia 03 de maio de 2016 ao Conselho Nacional de Educação, União Nacional dos Dirigentes Municipais de Educação (UNDIME)e Conselho Nacional de Secretários de Educação (CONSED), em sessão solene.

As disputas em torno do documento e de sua legitimidade ocorreram antes, durante e depois da publicação da primeira e da segunda versões pelo MEC. Houve, por exemplo, projeto do deputado Rogério Marinho ${ }^{3}$ visando transferir para a Câmara a produção e discussão da BNCC, ou seja, o projeto da BNCC seria proposto pelo poder executivo e aprovado no Congresso Nacional. A ideia de uma racionalidade técnica, contida no parecer ${ }^{4}$ do relator Átila Lira, esvaziada de conteúdo político, apresentava uma defesa de conteúdos mínimos e programas fechados. No mesmo parecer, evidenciou-se a retomada de um relatório da Câmara dos Deputados sobre Educação Infantil, produzido em 2003, que denunciou a falta de bases científicas para a alfabetização brasileira. Com o mesmo argumento de cientificidade, esse relatório de 2003 defendia a adoção nacional do método fônico e teve grande repercussão, mas não logrou resultados naquela época, voltando-se então para influenciar políticas estaduais e municipais.

Alguns desses movimentos foram denunciados em notas técnicas das equipes envolvidas na construção da BNCC. Outros movimentos de discussão ocorridos dentro do processo de produção da primeira e da segunda versões foram apresentados no Relatório entregue ao MEC e divulgado para várias entidades. (MICARELLO e FRADE, 2017).

A abordagem dos documentos da BNCC neste artigo, no caso da alfabetização, tem dois lugares enunciativos: aquele em que atuei na produção dos documentos de Língua Portuguesa da BNCC até a segunda versão, e outro em que atuo apenas como leitora da versão homologada.

Ao focalizar as questões da alfabetização e do ensino de Língua Portuguesa na BNCC, este artigo traz o cruzamento de duas abordagens: uma que se refere à análise dos documentos publicados nas versões da BNCC trazidas a público e outra que se refere a uma análise dos movimentos conceituais e de políticas de alfabetização na relação com as decisões oriundas da interpretação da estratégia 7.1 do PNE 2014-2024. 


\section{INTERPRETAC̣̃̃O DA ESTRATÉGIA 7.1 DO PNE 2014-2024 E SEUS IMPLÍCITOS}

O texto da estratégia de número 7.1 do Plano Nacional de Educação, que serviu de base para a formulação da BNCC, apesar de bem sintético, exige uma série de cuidados e interpretações. Abaixo, a meta:

7.1. estabelecer e implantar, mediante pactuação interfederativa, diretrizes pedagógicas para a educação básica e a base nacional comum dos currículos, com direitos e objetivos de aprendizagem e desenvolvimento dos(as) alunos(as) para cada ano do ensino fundamental e médio, respeitada a diversidade regional, estadual e local; (BRASIL, Plano Nacional de Educação 2014-2024, p. 61)

A existência de tal meta, que colocou como norma legal a formulação da BNCC, nesses termos, certamente não começou com a formulação do PNE (2014), uma vez que há vários antecedentes legais que anunciam essa necessidade. Por esse motivo, sua interpretação foi cruzada com a LDB, com as DCNs, assim como os pareceres do Conselho Nacional de Educação a ela anexados. Nas DCNs, são estabelecidas finalidades éticas, sociais e políticas para a educação brasileira e, ao compreender a educação como um direito e os sujeitos da educação em sua dimensão cultural e social, havia questões mais amplas que respaldariam a formulação de uma BNCC. Essas dimensões foram o arcabouço para construção dos direitos gerais e direitos nas dimensões éticas, sociais e políticas de cada segmento/etapa, até a segunda versão do documento.

\section{"PACTUAÇÃO INTERFEDERATIVA"}

A primeira parte da meta põe em relevo quais seriam os atores e instituições que deveriam participar do processo: secretarias estaduais e municipais de educação, tendo como representantes máximos o MEC, UNDIME e CONSED, e membros representantes das comissões de assessores e especialistas que foram indicadas por essas instituições para formulação da primeira proposta da Base. No caso de todas as equipes de assessores e redatores e daquela envolvida na alfabetização, havia, desde a primeira versão, um ato governamental nomeando publicamente os seus integrantes. No caso da alfabetização, havia representantes da região Sul, Sudeste, Nordeste, e todos os membros da equipe estavam participando do Pacto Nacional pela Alfabetização na Idade Certa (PNAIC). ${ }^{5}$ De um ponto de vista conceitual, então, pode-se dizer que não havia grandes disputas em torno do conteúdo do texto e da ideia de direitos de aprendizagem. 
Respeitando um processo de consulta pública mais amplo, a primeira versão do texto foi discutida com vários especialistas de universidades brasileiras convidados a se posicionar sobre o documento disponibilizado à consulta pública que incluía sujeitos e instituições da sociedade civil, entre setembro de 2015 e março de 2016. Nessa consulta, uma das áreas/componentes/temas que suscitou uma das maiores participações foi a proposta de Língua Portuguesa e de Alfabetização e uma das maiores participações ocorreu entre alfabetizadores, mostrando a força dos processos de formação na construção de repertórios comuns.

Uma análise da condução da terceira e da quarta versões, encaminhadas pelo MEC e seus parceiros, mostra que houve um rompimento, sem nenhuma transição, com as equipes anteriores e com a consulta pública realizada, embora tenha continuado uma espécie de consulta entre MEC e entidades como UNDIME e CONSED. Isso mostra que a disputa em torno do projeto final foi desenvolvida numa outra relação de poder entre MEC e secretarias de educação do país e outra equipe de coordenação. Assim, a ideia de pacto interfederativo também teve mais de uma interpretação.

\section{"COM DIREITOS E OBJETIVOS DE APRENDIZAGEM E DESENVOLVIMENTO DOS(AS) ALUNOS(AS)"}

Ao ler sobre os questionamentos que emergiram na construção da estratégia 7.1 do PNE,: constata-se que houve polêmica em relação aos termos, havendo uma disputa entre os termos "expectativas de aprendizagem" e "direitos e objetivos de aprendizagem e desenvolvimento", tendo vencido a segunda. Se trabalhamos com a concepção de direitos, a expressão "objetivos de aprendizagem" a eles vinculados desloca uma perspectiva individual e apenas cognitiva para uma ideia de direitos que responsabiliza a sociedade e os sistemas de ensino pela garantia desses direitos.

Se a primeira e a segunda versões procuraram ser coerentes com essa concepção, a mudança para a noção de competências e habilidades, que passou a vigorar na terceira e quarta versões, mostra que, mesmo quando uma concepção é "cercada" num documento, pode haver mudanças na sua interpretação. No caso da alfabetização, o termo "direitos de aprendizagem" já vinha sendo cunhado em alguns documentos, sobretudo no projeto de formação continuada do PNAIC, passando a fazer parte do repertório de mais de 360.000 professores que participavam desta política. 
Mesmo quando há uma meta construída em determinados termos, estes vão se intercambiando ou sobressaindo, segundo tendências defendidas pelos grupos que tentam colocá-las em ação. Nesse caso, a noção de direitos ficou mais clara na segunda versão, ao se colocar, como norte para toda a educação básica, determinados direitos éticos, sociais e políticos. No campo de Língua Portuguesa, a noção de interlocução e de interação pela linguagem em práticas situadas de uso da língua, além de habilidades comuns a todas as práticas, perpassou a escolha dos campos e dos gêneros discursivos a serem lidos, produzidos e analisados. A alfabetização, num cruzamento com esses campos de atuação, seria ressignificada, embora sua maior especificação tenha aparecido no eixo de conhecimentos sobre a língua e sobre a norma, visando dar maior visibilidade a essa faceta linguística. Nesse eixo, as principais capacidades de alfabetização ficaram mais concentradas nos $1^{\circ}$ e $2^{\circ}$ anos, sendo o $3^{\circ}$ ano o momento de consolidação.

A expressão "direitos e objetivos de aprendizagem e desenvolvimento" não supunha a delimitação de conteúdos até a segunda versão. A partir da terceira versão, a forma de ligação dos eixos com os objetivos sofreu uma alteração significativa: há eixos, conteúdos e habilidades. Assim, a ideia de direitos políticos, éticos e sociais mais amplos que pudessem estruturar a base não foi mais explicitada.

\section{"PARA CADA ANO DO ENSINO FUNDAMENTAL E MÉDIO"}

Essa outra expressão contida na estratégia 7.1 do PNE, também foi de difícil interpretação, negociação e acordo. De onde e por que uma proposta de construir objetivos ano a ano? Essa decisão tão importante para uma concepção de Base Nacional Comum Curricular teria passado, sem conflitos, pelo processo de validação em fóruns que geraram as metas do PNE? O que se soube é que esta meta foi construída no GT Qualidade da Educação, que contava com representantes de várias instituições.

O texto oficial de uma meta representa a ponta de um iceberg para quem não participou da sua formulação, uma vez que na própria alfabetização vários sistemas de ensino, professores e pesquisadores vinham trabalhando com a ideia de ciclo pedagógico. A implementação dos ciclos, na década de 1980, ocorreu num momento em que os métodos de alfabetização que se destinavam a um ano ainda funcionavam como uma espécie de bússola para as decisões curriculares, mas, a partir de sua implementação e da ideia de 
continuum, esses ciclos foram pensados para minimizar o problema do fracasso e da permanência, para acompanhar melhor a evolução das crianças e para respeitar melhor seu desenvolvimento. No entanto, embora possamos dizer que foram inegáveis os ganhos, havia uma falta de clareza sobre quais seriam as habilidades ou capacidades a serem adquiridas nesses anos e sobre qual seria uma progressão pensada nesse período. Essa espécie de estagnação teve uma mudança estrutural relevante, ao ser efetivada a política de ensino fundamental de nove anos, sinalizada na LDB em 1996 e sendo implementada nacionalmente em decorrência da Lei 11.274, de 06/02/2006.

Essas medidas de antecipação do ensino fundamental em um ano, considerando a dificuldade de implementar a obrigatoriedade da educação infantil no país, trouxeram muitos efeitos na alfabetização: a ampliação do ciclo inicial para três anos; a instabilidade e quebra de uma cultura escolar acostumada a trabalhar com crianças de sete anos; a discussão da relação entre educação infantil e ensino fundamental; a ideia de infância perpassando a educação infantil e o ensino fundamental e a necessidade de escolarizar respeitando seu desenvolvimento e direitos; e, no caso da alfabetização, a existência de um "hiato" ou lacuna criados pelo fato de os sistemas e professores ainda não saberem como conduzir esse um ano a mais que passou a compor o ciclo. Esse ponto de tensão gerou uma série de políticas nacionais que acabaram impactando as questões curriculares, na ausência de um currículo nacional que considerasse essa nova estruturação, como o Pro-letramento (2007), o PNLD (que teve início em 1996, mas passou a compor a ideia de coleção para o ciclo de três anos em 2010) e o PNAIC (2012).

O Pro-letramento tentou uma articulação entre capacidades de alfabetização e letramento, concepção que vinha sendo discutida no país e que vinha aumentando as expectativas sobre o que deveria compor a alfabetização, sobretudo a partir dos trabalhos de Magda Soares (2000). ${ }^{6}$ O primeiro fascículo especificava capacidades relativas aos eixos de compreensão e valorização da cultura escrita, leitura, apropriação do sistema de escrita, produção escrita e desenvolvimento da oralidade, para o ciclo de três anos. A estratégia para diferenciar ano a ano foi dada pela utilização dos termos "introduzir, trabalhar sistematicamente e consolidar". Nesse projeto, se os eixos de leitura e produção de textos vinham com a ideia de continuum no bloco de três anos, algumas capacidades relativas à aquisição do sistema alfabético de escrita ficavam demarcadas no $1^{\circ}$ (introduzir) e no $2^{\circ}$ e $3^{\circ}$ ano 
(trabalhar e consolidar). Embora pareça mais difusa a demarcação entre um e outro ano, o fato de assumir que a abordagem do sistema de escrita deveria ocorrer desde o $1^{\circ}$ ano demarcava uma tomada de posição. No entanto, ao cruzar os eixos, constatam-se outras tomadas de posição para a produção escrita, leitura e oralidade, para o $1^{\circ}$ e $2^{\circ}$ anos, explicitando-se expectativas de escrever segundo o princípio alfabético e as regras ortográficas, de revisar e reelaborar textos, de ler oralmente com fluência e expressividade e planejar textos orais, usando linguagem adequada aos contextos, com autonomia.

Oficializado cinco anos depois, o PNAIC avançou nas referências curriculares para alfabetização e matemática, embora não fosse esse um texto normativo ou mandatório. $\mathrm{Na}$ apresentação, reforça-se que "Uma primeira questão que se coloca ao discutirmos sobre as estratégias para a melhoria da educação é relativa à delimitação de conhecimentos, habilidades e capacidades a serem contempladas nas propostas curriculares" (BRASIL. 2012, p. 6). Mais adiante aparecem alguns parâmetros também relativos ao $1^{\circ}$ ano: "promover o ensino do sistema de escrita desde o primeiro ano do Ensino Fundamental e garantir que os conhecimentos relativos às correspondências grafofônicas sejam consolidados nos dois anos seguintes". (BRASIL, 2012, p. 7) (grifos nossos)

No que tange ao que se delimitava ano a ano, mantinha-se a mesma ideia de introdução, trabalho sistemático e consolidação que havia no Pro-Letramento. No documento do PNAIC, a definição ano a ano que mais se destaca, se comparada ao continuum dos outros eixos e sua mesclagem ano a ano, se refere à apropriação do sistema de escrita alfabética no $1^{\circ}$ ano do ensino fundamental. É nessa especificidade da faceta linguística que o trabalho de introduzir, trabalhar e consolidar aparece basicamente no $1^{\circ}$ ano da escolarização básica, ao mesmo tempo em que se desenvolviam capacidades de ler e escrever textos neste mesmo ano. Abarcando a formação de 360.000 alfabetizadores, esse projeto teve o poder de configurar acordos e repertórios comuns para o primeiro ciclo do ensino fundamental. Não por coincidência surge atrelado a ele a Avaliação Nacional de Alfabetização (ANA). Essas estratégias estavam em discussão desde 2008 e foram substanciadas na meta 5, "alfabetizar todas as crianças até o terceiro ano do ensino fundamental" (PNE 2014/2024). Embora com o limite do $3^{\circ}$ ano, os documentos de formação mostram que as expectativas de alfabetizar antes desse limite já estavam postas.

Mesmo com esse quadro de referências, não foi simples interpretar ou construir objetivos ano a ano. Uma primeira disputa 
interna no trabalho de formulação da BNCC na alfabetização foi a tentativa de manter o bloco e seus objetivos para o ciclo e não por ano, havendo uma primeira proposta de repetir todos os objetivos de alfabetização no primeiro bloco de três anos e repetir, no segundo ciclo, os objetivos específicos desse período.

$\mathrm{Na}$ verdade, a grande questão que se colocava para toda a BNCC era o enfrentamento da demanda ano a ano vinculada a uma ideia de progressão. Os documentos orientadores, como os PCNs, apresentavam critérios muito vagos, como o tratamento cíclico e aprofundamento gradativo do mesmo tema, relação com os conhecimentos prévios dos alunos, relação entre tipo de conteúdo e grau de autonomia e aprofundamento em relação às possibilidades de compreensão dos alunos, deixando a cargo das escolas o desafio da progressão - como na afirmação nos PCNs de que "este documento indica critérios, mas a sequenciação dos conteúdos de ensino dentro de cada ciclo é responsabilidade da escola" (PCNs. Língua Portuguesa. p.44-45).

A análise prévia dos currículos estaduais, primeira etapa do trabalho da equipe de formulação da BNCC, em 2015, demonstrava que eram tímidos os esforços para esta construção da progressão:

[...] No que concerne aos anos iniciais do Ensino Fundamental, embora haja referências recorrentes ao bloco pedagógico, composto pelos três primeiros anos do Ensino Fundamental, o tratamento dado a esse bloco ainda é segmentado, apresentando-se expectativas ou objetivos de aprendizagem anuais, em geral com poucas articulações entre os anos. Tais articulações, quando existem, fazemse pela repetição das expectativas ou objetivos em diferentes anos. (Grifos nossos. Referências ao relatório do grupo de estudos dos currículos nacionais feitas em MICARELLO e FRADE 2017, p. 62)

A solução adotada na primeira versão para a progressão repercutiu nos pareceres críticos de especialistas, com alguns indicando a viabilidade de uma progressão conforme a complexidade dos textos, enquanto outros não apoiavam essa perspectiva. Certamente essa concepção se relaciona diretamente com a alfabetização, no seu sentido de maior ou menor autonomia para decifração, desconsiderando a atividade mediada. A progressão pela extensão dos textos e seus aspectos gramaticais ganhou relevo em seminário com especialistas e leitores críticos e, não havendo concordância com esse critério, o mesmo não foi adotado na segunda versão.

A ideia de progressão na segunda versão da BNCC, apresentada pela equipe ao CNE em sessão pública, foi anunciada como resultante das definições de:

- $\quad$ presença ou ausência de mediação; 
- complexidade dos textos para a leitura autônoma (tamanho, tema, estruturas, gêneros);

- gêneros (dos mais simples e cotidianos aos mais complexos e de uso menos frequente);

- abordagem de aspectos mais amplos, como a função social dos textos, para depois aprofundar sobre sua forma de composição (letramento e cultura escrita);

- habilidades, das mais simples, como identificar, às mais complexas, como comparar e avaliar (abordagem cognitiva);

- critérios relativos a contextos e públicos para a produção escrita.

$\mathrm{Na}$ segunda versão, havia a expectativa de que o contato com textos de maior complexidade se daria pela atuação e mediação do professor, e não apenas pela leitura e escrita autônomas. Desde o $1^{\circ}$ ano, havia gêneros textuais mais usuais de cada campo de atuação ${ }^{7}$ e que se organizavam com os tipos narrativo, expositivo, argumentativo e injuntivo, permeando a experiência com a língua, nos quatro campos de atuação. Assim, a progressão na alfabetização não só funcionou para aspectos de conhecimento da língua e da norma, como para os outros eixos que envolviam leitura e produção de textos.

Embora o tema da progressão pelo tamanho e natureza dos textos tenha perdido espaço na segunda versão, essa concepção voltou a aparecer na terceira versão, que explicitava os temas, recursos e nível de textualidade, tamanho e tipo de textos, conforme definição do eixo de leitura para o $1^{\circ}$ ano:

\footnotetext{
Práticas de compreensão e interpretação de textos verbais. Verbo-visuais e multimodais. Texto do cotidiano próximo e da vivência e interesse ao aluno, com imagens que forneçam informações adicionais, tema apropriado à faixa etária do leitor (crianças) e nível de textualidade adequado; vocabulário previsível, orações e período curtos e recursos predominantemente denotativos; no caso de textos verbais com aproximadamente 200 palavras. (grifos nossos) (BRASIL, BNCC, terceira versão, p. 70).
}

No $2^{\circ}$ ano, a alteração nesse tópico de leitura vem apenas na extensão de textos, 300 palavras no $2^{\circ}$ e 400 no $3^{\circ}$, com a modificação da seguinte parte: vocabulário familiar, disposição e ordem direta das proposições. Essa modificação não altera em nada a concepção presente desde o $1^{\circ}$ ano e que vai prevalecer até o $5^{\circ}$ ano, mudando a quantidade de palavras para 500 no $4^{\circ}$ ano e 600 no $5^{\circ}$ ano, quando aparecem a possibilidade de enriquecimento do léxico e os recursos 
expressivos denotativos e conotativos. Ou seja, pelo critério seriam excluídos os textos curtos que escapassem ao caráter denotativo, como notícias, poemas, publicidade, entre outros.

$\mathrm{Na}$ versão homologada, a progressão relativa aos textos a serem lidos e escritos são genéricas e muito agrupadas, revelando que não houve um trabalho de refinamento da progressão. Entretanto, o texto introdutório do texto aprovado problematiza a ideia de progressão para leitura e escrita, lembrando a necessidade de conjugar vários fatores: a necessidade de articular a diversidade de gêneros, o uso de habilidades de leitura, a cultura digital e a diversidade cultural, além da complexidade textual "que se concretiza pela temática, estruturação sintática, vocabulário, recursos estilísticos utilizados, orquestração de vozes e linguagem presentes no texto" (p.73). Ao manter a noção de atividade mediada e autônoma que constava desde a primeira versão, não haveria impedimento de contato com outros tipos de texto desde a alfabetização. Essa concepção deixa brechas para que não se restrinja a alfabetização.

Há várias questões envolvidas em algumas terminologias que aparecem na versão homologada, como a ideia de "mecânica" ou separação entre alfabetização e ortografização, que não correspondem às concepções defendidas em outros documentos, como os do Pacto Nacional pela Alfabetização na Idade Certa (2012), nem a questões terminológicas relacionadas ao termo alfabetização. Há também inovações que precisam ser melhor interpretadas, quando se usam os termos análise linguística/semiótica e seus reflexos na conceituação de alfabetização. No entanto, embora haja algumas concepções em comum entre a segunda e a quarta versões quanto ao letramento, na versão homologada aparece explicitamente um recorte no ciclo, ao se delimitar em dois anos a alfabetização (BRASIL, BNCC, 2017, p. 56).

Em outra parte do documento, aparece a relativização - "que pode se dar em dois anos” (BRASIL, BNCC, quarta versão, 2018, p. 89) - mas a decisão é reforçada na Resolução de n. 2 do CNE, nos seguintes termos:

Art. 12. Para atender o disposto no inciso I do artigo 32 da LDB, no primeiro e no segundo ano do Ensino Fundamental, a ação pedagógica deve ter como foco a alfabetização, de modo que se garanta aos estudantes a apropriação do sistema de escrita alfabética, a compreensão leitora e a escrita de textos com complexidade adequada à faixa etária dos estudantes, e o desenvolvimento da capacidade de ler e escrever números, compreender suas funções, bem como o significado e uso das quatro operações matemáticas. (Grifos nossos) BRASIL, Resolução CNE- CP No 2, de 22 de dezembro de 2017. 
Considerando o que, de fato, aparece nas chamadas habilidades e sua progressão nos três primeiros anos do ensino fundamental na versão homologada, o que significa o corte anunciado de dois anos, que também estava presente desde a terceira versão da BNCC? Uma estratégia discursiva e política para demarcar posições? Aumento da exigência ou redução das expectativas, considerando o que se apresenta na BNCC e sua relação com novas avaliações em grande escala?

Analisando os objetivos que estavam na segunda versão e comparando com as habilidades que constam até o $2^{\circ}$ ano da quarta versão, vemos que não há tanta diferença, mas não podemos esquecer que essas decisões podem repercutir em seriação, em retenção no $2^{\circ}$ ano, em redução de expectativas que podem alterar a interpretação de resultados de avaliação, em rompimento com a ideia de coleção que foi construída para os materiais didáticos do PNLD, ferindo o princípio de bloco pedagógico defendido nas DCNs (p.122).

Um fator é a conquista de melhores resultados em função da ampliação da entrada dos alunos no EF e da universalização da educação infantil, que mostrará, numa perspectiva histórica, que o tempo de uma alfabetização mais plena pode sofrer mudanças; outro é considerar que se pode decretar esse tempo que não é apenas pedagógico, mas também cultural, pois isso trará consequências políticas e pedagógicas. Por isso, é preciso ver as mudanças de resultados a longo prazo, considerando a conquista de direitos à escolarização, e cotejar o texto da BNCC com outras legislações, com as DCNs e o PNE, para achar um equilíbrio e novos pontos de contra-argumentação. Isso numa sociedade de direitos...

\section{"RESPEITADA A DIVERSIDADE REGIONAL, ESTADUAL E LOCAL"}

A última expressão da estratégia 7.1 era praticamente impossível de ser resolvida no documento geral da BNCC, a não ser como anúncio de seu desdobramento. Não se tratava, certamente, de uma divisão de carga horária, mas da construção de um tipo de documento que apontasse para a universalidade de objetivos de aprendizagem baseada em objetos linguísticos, ao mesmo tempo associados a possíveis modos de organização. No caso da alfabetização, na segunda versão da BNCC, a escolha por objetivos de natureza linguística, associados a objetivos relacionados às práticas situadas de uso da escrita - consubstanciadas nos termos "campo da vida cotidiana", "campo literário", "campo político-cidadão" e "campo investigativo" foi decorrente de escolhas políticas e de determinada concepção de linguagem. 
A organização dos objetivos de Língua Portuguesa em todos os campos de atuação e o estudo das normas e convenções supunham a sua aplicação em práticas situadas a serem definidas por contextos locais. Embora houvesse um aceno para os gêneros discursivos presentes nos campos de atuação e em suas características linguísticas e discursivas, nenhum desses objetivos determinava contextos, metodologias, materiais didáticos, formas de avaliação ou reprovação. Assim, uma articulação entre um documento que serviria de referência geral e as práticas locais de uso dos textos supostamente garantiria o respeito à diversidade regional, estadual e local.

A concepção de que a alfabetização e o ensino de Língua Portuguesa deveriam ocorrer em práticas situadas, denominadas campos de atuação, desapareceu como eixo organizador na terceira versão, mas foi recuperada na versão homologada, mostrando que a equipe envolvida na etapa final adotou uma concepção próxima à que estava na primeira e na segunda versões. Ou seja, embora se acenasse com contextos, estes não definiam as situações de uso, os temas, nem especificavam destinatários ou suportes de circulação, vários destes a serem definidos localmente. Essa apropriação, por cada sala de aula, dos usos e situações se relaciona com a ideia de letramentos sociais desenvolvida por Brian Street (2014), ou seja, o desenvolvimento das habilidades (visão mais autônoma) terá que dialogar com as práticas de sala de aula (modelo ideológico do letramento).

No entanto, não podemos nos descuidar de que, dependendo da interpretação das equipes que continuarão a produzir suas referências curriculares, os aspectos mais universais do conhecimento podem não ser relacionados a experiências locais, ficando apenas o investimento pedagógico nas habilidades. Os textos normativos, como a resolução do CNE de dezembro de 2017 e o próprio texto final da quarta versão, voltam a reforçar a autonomia pedagógica e as questões a serem decididas localmente, deixando brechas para os sistemas de ensino e para os professores.

\section{REFERÊNCIAS}

BATISTA, A. A. G e RIBEIRO, W. M. Consensos e dissensos em torno de uma Base Nacional Comum Curricular no Brasil. Relatório de Pesquisa. São Paulo, 2015. http:// ftp.cenpec.org.br/com/portalcenpec/biblioteca/Consensos_e_Dissensos_Relatorio_ Pesquisa_Cenpec_Final.pdf

BRASIL. Lei $\mathrm{n}^{\mathbf{0}} \mathbf{9 . 3 9 4}$, de 20 de dezembro de 1996. Estabelece as diretrizes e bases da educação nacional. Diário Oficial da União, Brasília, DF, 23 dez. 1996. Disponível em: <h p://www.planalto.gov.br/ccivil_03/leis/19394.htm>. 
BRASIL - Secretaria de Educação Fundamental -Parâmetros Curriculares Nacionais: Língua Portuguesa. Brasília., 1997. 144 p.

BRASIL - Lei 11.274, de 06/02/2006. Altera redação dos artigos 29, 30, 32 E 87 da Lei 9.394, de 20 de dezembro de 1996, que estabelece Diretrizes e Bases da Educação Nacional, dispondo sobre a duração de 9 (nove) anos para o ensino fundamental, com matrícula obrigatória a partir dos 6 (seis) anos de idade. Disponível em https://legis.senado.leg.br/ norma $/ 572813$

BRASIL. Ministério da Educação. Secretaria de Educação Básica. Pró-Letramento: Programa de Formação Continuada de Professores dos Anos/Séries Iniciais do Ensino Fundamental: alfabetização e linguagem. Brasília: 2008. 364 p.

BRASIL. Secretaria de Educação Básica. Diretoria de Apoio à Gestão Educacional. Pacto Nacional pela Alfabetização na Idade Certa: Formação do professor alfabetizador. Caderno de apresentação. Ministério da Educação, Secretaria de Educação Básica, Diretoria de Apoio à Gestão Educacional. -- Brasília: MEC, SEB, 2012. 76p.

BRASIL. Ministério da Educação. Secretaria de Educação Básica. Secretaria de Educação Continuada, Alfabetização, Diversidade e Inclusão. Secretaria de Educação Profissional e Tecnológica. Conselho Nacional da Educação. Câmara Nacional de Educação Básica. Diretrizes Curriculares Nacionais Gerais da Educação Básica / Ministério da Educação. Secretaria de Educação Básica. Diretoria de Currículos e Educação Integral. Brasília: MEC, SEB, DICEI, 2013. 562p.

BRASIL. Ministério da Educação. Base Nacional Comum Curricular. Proposta preliminar. Segunda Versão Revista. Brasília. Abril, 2016. 651 p.

BRASIL. Ministério da Educação. Base Nacional Comum. A Educação é a base. Brasília. S/D. 396p (terceira versão)

BRASIL. Ministério da Educação. Base Nacional Comum. A Educação é a base. Brasília. S/D. 472p. (quarta versão). Divulgada em 19 de março de 2018

GRUPO de trabalho alfabetização infantil : os novos caminhos : relatório final. Brasília : Câmara dos Deputados, Coordenação de Publicações, 2003.

MICARELLO, H.. E FRADE, I. Base Nacional Comum curricular. Relatório Final sobre o Processo de Elaboração das versões 1 e 2. Centro de Alfabetização Leitura e Escrita - CEALE - da Faculdade de Educação da Universidade Federal de Minas Gerais. Abril 2017. 202p. (enviado à Secretaria de Educação Básica do Ministério da Educação, ao CNE e ANPEd).

PLANO NACIONAL DE EDUCAÇÃO 2014-2024 [recurso eletrônico]: Lei no 13.005, de 25 de junho de 2014, que aprova o Plano Nacional de Educação (PNE) e dá outras providências. Brasília: Câmara dos Deputados, Edições Câmara, 2014. 86p.(Série legislação; n. 125) http://www.planalto.gov.br/CCIVIL_03/_Ato2011-2014/2014/Lei/L13005.htm. Acesso em: 19 nov. 2018.

SOARES, M. Letramento: um tema em três gêneros. Belo Horizonte. Autêntica. 2000.125 p. SOARES, M. Alfabetização: a questão dos métodos. São Paulo. Contexto. 2016. 377p.

STREET, B. Letramentos Sociais. Abordagens crítica do letramento no desenvolvimento da etnografia e na educação. São Paulo. Parábola Editorial, 2014. 238p. 


\section{NOTAS}

1 Movimento liderado por grupos políticos e da sociedade civil brasileira, que fere o direito constitucional de liberdade de ensino e pluralismo de concepções pedagógicas. Este movimento repercute na defesa da censura feita pelas famílias e pela sociedade em relação às abordagens da diversidade humana e social na educação escolar, sobretudo as que se referem à diversidade de gênero, religião e ideologias políticas.

2 A primeira portaria, como ato de designar uma comissão foi publicada no Diário Oficial da União, seção 1, N. 114. 18 de junho de 2015 e a segunda, com os nomes dos especialistas, foi publicada no Diário Oficial da União, seção 2, N. 132, de 14 de julho de 2015

3 Projeto de Lei $N^{\circ}$ 4.486, de 2016 que "Altera a Lei no 13.005, de 25 de junho de 2014, Plano Nacional de Educação - PNE, visando que a Base Nacional Comum Curricular BNCC, mediante proposta do Poder Executivo, seja aprovada pelo Congresso Nacional.",

4 Parecer consultado em https://avaliacaoeducacional.files.wordpress.com/2017/09/ parecer-ce-30-08-2016.pdf

5 Trata-se de uma política de formação de professores alfabetizadores alicerçada em direitos de aprendizagem, implementada em 2012 pelo MEC.

6 Num contexto em que alfabetização foi subsumida ao conceito de letramento, Magda Soares (2016) dá visibilidade à faceta linguística da alfabetização. A autora aponta que a esta faceta devem ser articuladas outras, que estão relacionadas ao letramento, a interativa e a sociocultural, observando que para cada faceta há objetos e metodologias diferentes.

7 A definição por campos de atuação foi estabelecida por sua relação com os usos sociais dos textos orais e escritos em diferentes esferas da vida .No documento, a categorização desses campos resultou em quatro categorias: : campo da vida cotidiana, campo literário, campo político-cidadão e campo investigativo.

Submetido: 03/02/2019

Aprovado: 17/10/2019

Contato:

Rua Pioneiros da Paz, nº252|Santa Amélia Belo Horizonte $|\mathrm{MG}|$ Brasil

CEP 31.555-320 